\title{
Reflexiones sobre la perspectiva
}

\author{
Jesús VIÑuALES *
}

Sobre el descubrimiento de la perspectiva en el Renacimiento se ha escrito y hablado con profusión. A estas alturas están ya claros el hecho y el significado. Que resulta ser un descubrimiento de tal importancia que ha mediatizado a las artes plásticas hasta el siglo Xx. Que desde las vanguardias históricas somos conscientes de que se trata solamente de un modo de representación y ni siquiera el mejor plásticamente hablando. Tampoco conmueve este sistema en un momento en que se utiliza o no según covenga, pasando a ser una conquista mas del acervo cultural y técnico humano. En este sentido estas reflexiones pueden resultar superfluas. Pero a nosotros nos siguen interesando una serie de circunstancias en torno a este descubrimiento. ¿Es realmente un descubrimiento o sólo una eclosión que se venía gestando tiempo atrás? ¿Se trata de una fórmula científica o la puesta a punto de ley de una sabiduría empírica? ¿Supone el término de una evolución plástica o un desvío, una ramificación que se impuso a otras posibles y que podrian haber resultado más "sabias"? ¿Por qué se impuso, entonces? ¿Por qué ha mediatizado durante casi cuatro siglos la visión occidental del arte? ¿Por qué aun en la actualidad, que sabemos de sus limitaciones, continúa ejerciendo tanto "tirón" en la visualidad del arte? ¿Supuso un acierto en el sistema de representación como la ley de la gravedad de Newton en la física? ¿Estamos determinados a contar con ella para un "campo" concreto como lo estamos a utilizar la geometría euclídea para unas concretas condiciones? En fin, existen multitud de interrogantes sobre las que queremos reflexionar y aportar nuestro criterio por si añade algo novedoso.

Parece ser que Bruneleschi en dos tablas pintadas en 1415 actualmente perdidas reprodujo por primera vez imágenes de Florencia utilizando un método menos "empírico" de representación de la apariencia fenoménica. Se cuenta que recubiertas de plata bruñida, a modo de un

* Dpto. H. ${ }^{a}$ del Arte. UNED. 
espejo, reflejaban como tal espejo, esto es, inversamente lo que Bruneleschi veía desde una localización concreta. Repasadas por el artista siguiendo las líneas fundamentales, practicó un agujero central por donde se miraba la imagen que las tablas reflejaban a su vez en otro espejo puesto enfrente. Lo que el espectador veía se correspondía con lo que veía de la ciudad, si se situaba en el mismo punto de observación que había motivado el reflejo. Ahora más exactamente, pues al invertirse de nuevo la imagen quedaba acorde con la real. Es probable que esta experiencia fuera así o sólo fuera una etiología como la manzana de Newton. En cualquier caso sabemos que Bruneleschi intenta un método de perspectiva nuevo, de punto de fuga único tanto en su arquitectura como en el concurso para las puertas del Baptisterio de Florencia. $Y$ por supuesto Alberti en su tratado "De pictura" de 1435 ya incorpora "científicamente" tales descubrimientos. Pero Alberti extrapola tal cientifismo cuando se refiere a la perspectiva como "una ventana abierta" o cuando exclama: «Por fin la perspectiva me hace ver el mundo como Dios lo ha visto", sobre lo que volveremos mas adelante.

Durante toda la Edad Media el sistema de representación va cambiando lentamente, acercándose empíricamente al sistema de perspectiva de punto de fuga único. Naturalmente este cambio es casi imperceptible, ya que el concepto de espacio también cambia lentamente, pero se puede rastrear paso a paso, como ha puesto de manifiesto Jean Paris en las reprentaciones de la Virgen María. Desde la consideración espacial sagrada de la Theotocos (asimilable al Pantocrator) a la humanista ocurren fases esclarecedoras de cambios mínimos pero constantes. La Panaia, Ilamada en ocasiones también Playtera enmarca y "crea" todo el espacio, ella sola, casi totalmente simétrica y de mirada frontal. El espacio está delante, ella, desde fuera, lo crea. Enseguida la Theotocos introduce algo humano, el hijo, esto es, se apropia de un poco de espacio. La suerte está echada. Ahora el espacio en lenta pendiente se va a adueñar de María. Al principio el Niño es frontal, rígido, pero pronto se desvía un tanto hacia un lado, creando un espacio nuevo que se agranda cuando la Madre aparece sentada con el Niño en las rodillas. Otro rasgo humano. La introducción del globo terráqueo que sostiene el Niño, el asiento, el escabel sobre el que descansan los pies, da ocasión de abrir nuevos espacios. Despues se introducen ángeles que miran todavía hacia adelante, pero que pronto mirarán al grupo de Madre-Hijo, lo que supone un nuevo concepto espacial. Cuando María deje de mirar al frente para dirigir la mirada al hijo que pronto también mirará a su madre, el espacio abierto es impresionantemente humano. Se refuerza aún mas en la Glyptophilusa, en tierna caricia y rostro contra rostro. La entrada de donantes al lado del escabel y que miran a la madre y el hijo supone una abertura "grande" por donde 
se van a "colar" los espectadores. La Galactotryphusa o Virgen de la leche humaniza totalmente el espacio. Una versión ya de finales de la Edad Media de la Glyptophilusa que enlaza claramente con las madonas del Renacimiento, en que la madre se desentiende del espectador y mira y juega con el niño, en un paisaje con arquitecturas... determina el cambio espacial de tal modo que ya está dispuesta a ser mirada, como desde "una ventana abierta" en clara correspondencia con la representación teatral de un «misterio». El espacio ha dejado de ser sagrado. Ya no es creado por Dios o por la Madre sino por el hombre que enmarca, elige, sitúa e introduce los personajes en un espacio creado o ideado por él. El cambio de mentalidad está a punto para descubrir la perspectiva de una manera "científica" ya que empíricamente hablando muchas de estas obras se acomodan a una visión perspectivesca siguiendo una práctica visual, a la que ya Plotino había hecho referencia cuando habla de "aminoración que es difusión para el color y disminución para el tamaño». Falta solo una ley referencial.

Es evidente que la evolución ideológica resulta imprescindible para llegar a la perspectiva. Esta evolución viene marcada por variantes múltiples de las que aquí señalamos algunas, ya que son conocidas, como el crecimiento económico, las nuevas técnicas de aprovechamiento de la fuerza (yugo), nuevos pueblos, las Universidades, la filosofía positiva de un Ockam, la numeración arábiga que impulsa el cálculo matemático, la pasión por la óptica en la Baja Edad Media, el conocimiento de la geometría de Euclides o de la astronomía de Eudoxio o de los problemas mecánicos y de la luz...

Con todo, creemos que la razón fundamental no reside sino en el cambio del espíritu humanista en la concepción del Cosmos, lo que enlaza con la cuestión anterior de la representación de la Virgen. Es el hombre el que se decide a explicar el Cosmos, y busca denodádamente un sistema de referencia mas objetivo que la simbología filosófica. El interés por la Astronomía, primera explicación del Cosmos, va a resultar decisiva en este intento. La Astronomía, dice Poincaré, fue la que nos enseñó la existencia de las leyes. En este caldo de cultivo. Copérnico hacia 1530 tiene concluido su "De revolutione orbis terrarum", aunque no se publique hasta más tarde. Los artistas, como es lógico, participan de este ambiente.

El sabio renacentista no es un científico en el sentido moderno de la palabra. En el Renacimiento la realidad científica se compone «exclusivamente" de los, acontecimientos apreciables por los sentidos (nihil est in intellectu... aristotélico) y reproducible, en parte, por la experiencia humana (“visión» especialmente). En este sentido el sistema que desarrollará Copérnico y que estaba en el ambiente, como hemos dicho, trata de 
establecer un modelo universal en el que tengan cabida los hechos del Cosmos que el hombre podía aprehender por los sentidos. $Y$ en consecuencia, por el intelecto. Este modelo será el matemático, concebido como un marco de referencia único y global, cuantitativo y verificable.

En la aceptación de este modelo tiene mucho que ver la óptica, la geometría euclídea, la tradición pitagórica, la filosofía okcamiana y las Escuelas de San Victor o de Chartres. Es claro que por lo menos desde Euclides y la formulación de su famoso $5 .^{\circ}$ postulado (el de las paralelas) se conocían no sólo empíricamente sino científicamente las tres dimensiones. En un mundo agrícola, las dimensiones mas usadas visualmente, sin embargo, son dos: la línea y el plano. Con esto no decimos que no se supiera cubicar. Tanto la arquitectura, escultura como las medidas de uso cotidiano agrarias o de capacidad, así como la experiencia diaria de los cuerpos nos dejarían por mentirosos. Pero la verdadera conciencia de la tridimensionalidad del cosmos sólo se hace relevante con fuerza cuando el hombre se "ve" dueño del cosmos, en el centro de todas las cosas y tiene que recurrir a la Astronomía en una explicación rigurosa del mismo. Queremos decir que existe una variación de acento y que consiste en que el hombre se siente responsable de una explicación racional y por lo mismo medible, cuantificable, referencial de los acontecimientos del cosmos, que mas adelante llevará a Kepler a la formulación de sus tres tesis. Con la geometría de Euclides en la mano, ahora bien conocida, y puesto a observar el Universo, el hombre renacentista tiene que recurrir a la óptica y a las leyes que ya conoce de la misma, entre ellas la propagación de la luz en línea recta. $Y$ aquí tenemos a nuestro científico observador del cielo mirando con un "único ojo", tomando referencias desde un "único punto in móvil», comparando con otras referencias igualmente tomadas desde otro "único punto inmóvil», y con un «solo ojo», ya que es la manera, en aquel tiempo, de poder llegar a cierta conclusión medible y fiable. Algo que empíricamente ya sabían los arqueros y ballesteros. Cotas de medición que serán importantes para el desarrollo de la ciencia y que inmediatamente van a hacer sentir la necesidad de una "representación" del espacio nueva. Esto es, desde un punto único, con un solo ojo, hacia una cota única, dejando aparte todas las restantes circunstancias de la visión: el sistema bifocal humano, la curvatura da la retina, la movilidad del globo ocular y de la cabeza, la zona macular, el paralelaje de los astros, etc, etc. Evidentememte, la realidad así vista no es la realidad fenoménica que el hombre ve o percibe, ni siquiera tal como la ve, ya que sabemos por teoría de la percepción que la visión fenoménica es un conjunto resultante de muchas informaciones, de muchos puntos de vista, desde muchos ángulos, contando con la memoria, con la corrección del entendimiento sobre el dato sensible, con innumerables referencias al es- 
pacio tridimensional y por supuesto contando con el tiempo. Además cualquier tipo de percepción viene enmarcada por otra serie de conocimientos o condicionamientos culturales, experiencias sensibles o científicas e incluso ideológicas, políticas, sociales, religiosas, etc. La percepción anuclea alrededor de un dato, y ese dato es elegido por una inmensa cantidad de condiciones y variables. Así pues la perspectiva central rigurosamente aplicada no supone la visión perfecta de la realidad, ni siquiera una representación, igualdad en un plano, de la visión tridimensional del espacio por el ojo humano. En muchos aspectos y refiriéndonos concretamente a la pintura (en todas sus variedades y soportes) muchas obras del último gótico están mas cercanas a la manera de percibir humana que las obras renacentistas empeñadas en una aplicación rigurosa de las leyes de la perspectiva. ¿Por qué triunfa la perspectiva? La experiencia empírica evolucionando sin duda tomaría otras direcciones que el descubrimiento de la perspectiva, por la razón que antes hemos apuntado, esto es, porque la experiencia empírica tiende a acercarse a la visión fenoménica humana con la "complejidad" de los datos suministrados por la percepción, contando con todas esas variables que hemos enunciado anteriormente: bifocalidad, curva retiniana, memoria, "nichos» referenciales tanto culturales como simbólicos (p.e. la cueva en la representación de San Jorge, la concha en la de Venus...). Así pues, para nosotros el descubrimiento de la perspectiva rompe una evolución empírica y toma un camino diferente, mucho mas abstracto, mas analítico y por lo mismo, menos complejo y realista. ¿Por qué triunfa? Precisamente por estas cualidades que estaban en el ambiente del espíritu renacentista. Una explicación racional del Universo exige un sistema convencional que sea mas simple, que reduzca la complejidad del cosmos a unas posibilidades de medición. Los renacentistas pitagóricos harán suya una afirmación atribuida al filósofo: «la realidad es de índole matemática", en su afán por la medida y el número. Un sistema "correcto de representación» del espacio exige dejar fuera toda “intuición" y adoptar un análisis de partes que puedan fácilmente ser verificadas, mientras que el «todo" es inverificable. Una reducción a cantidad concreta, aislada, conforme con unas reglas tomadas de una geometría convencional reune los requisitos fundamentales por donde va a avanzar la ciencia. El señuelo, por otra parte es formidable, ya que se cree y se creerá que las convenciones de la ciencia lógicamente trabadas, rigurosamente deducidas, conducen a leyes que se verifican en la realidad, al menos en el campo de la realidad fenoménica analizado, con lo que la igualdad entre leyes de la naturaleza y leyes del conocimiento está servida. De ahí la frase de Alberti: "Ahora conozco al mundo como Dios lo ha visto". Téngase en cuenta que a Dios se le representa simbólicamente con un "solo ojo" dentro de un triángulo, ya que se supone que 
el conocimiento divino se adecúa lógicamente con toda ley de comportamiento cósmico y humano. Es tan fuerte el éxito que se obtiene de "acotar" un "trozo" de realidad y compararle y referenciarle a un "módulo" abstracto, convencional, hipotético, que la ciencia hasta nuestros días ha caminado por esta senda con resultados positivos. La formalización matemática es tan seria y bien trabada que resulta ser la ciencia formal por excelencia, y en este sentido todas las ciencias actuales miran el modelo matemático, incluso aquellas que simulan o pretenden rechazarlo. Ya que al ser lo real inaprehensible se toma su formulación como substancial. Si aun en nuestros días sigue "emocionando" este poderío de la ciencia, o mejor de estos métodos, cuando conocemos la relatividad, la indeterminación, la reducción fenomenológica, la probabilidad, el azar, el «ruido", el "despilfarro".. no es extraño que al hombre del Renacimiento le entusiasmara tal cambio, abandonando la empiria, mucho mas dificil de someter y de comprehender en un sistema. Lo que perdía en sensación lo ganaba en apariencia; lo que perdía en complejidad vivencial lo ganaba en simplicidad verificable.

Así pues, es evidente que la experiencia visual es mas compleja que la mera representación perspectivesca. $Y$ hemos dicho que este tipo de representación es convencional. $Y$ por abundancia tendríamos que afirmar la convencionalidad de todos los tipos de representación, lo que nos llevaría a un relativismo incapaz de darnos alguna imagen real. Por contra, si afirmamos que la perspectiva es el sistema correcto de reproducción del espacio real (GAURICUS, 1504) tendríamos esa igualdad entre las leyes de lo real y de la representación, lo que nos llevaría a un determinismo absoluto, además de caer en una concepción del espacio, no admitida ya, después de la teoría de la relatividad general.

Gombrich habla mas bien de "equivalencia", que se opone tanto a igualdad como a convencionalidad. Estas equivalencias con lo real son múltiples y variables. Por eso toda representación visual puede ser equivalente a lo percibido, siempre que acotemos las condiciones. La perspectiva sólo "funciona" como representación de lo que se ve desde un único punto de mira, inmóvil, con un ojo inmóvil, condiciones en las que funcionan las leyes de la óptica y la geometria de Euclides. Despreciando por supuesto, muchas otras variables y descontando igualmente una serie de leyes de la percepción como la memoria, el ajuste visual, la experiencia, la cultura, otras leyes físicas,.... Con aquellas condiciones, la perspectiva no es puramente convencional, sino equivalente. Tanto Gombrich como otros científicos (Hawking) se basan en las leyes de la selección natural para presumir que esta equivalencia «vale», y por eso se puede explicar el salto cualitativo que supone el descubrimiento de la perspectiva sobre otras posibles vías de representación. Se impone lo mas fácil de 
verificar, lo mas cómodo de medir, lo mas riguroso en universalidad y lo mas abstracto y general sobre lo concreto-particular. Pero, ¿son "equivalentes" nuestras leyes con las del universo? Y contesta Hawking: Sí, porque de otro modo no estaríamos haciendonos esta pregunta, esto es, no estaríamos. Dejando aparte este problema tan interesante que nos llevaría a formularnos si no existirán otros mundos con otras leyes, tendríamos al menos que preguntarnos si dentro de nuestras leyes las hay más equivalentes y menos equivalentes. $O$ si las leyes de la selección natural son tan ciertas que nos inducen a absoluta confianza en nuestros descubrimientos científicos, afirmaciones todas ellas muy discutidas y discutibles.

El hecho de que todas las leyes que conocemos se verifiquen en la Experiencia, menos las más extremas que no podemos verificar todavía, y es posible que no se puedan verificar nunca, aunque esto no supone mayor problema ya que bastan las leyes de verificabilidad, nos da confianza en que el Universo no se comporta arbitrariamente y que podemos llegar a conocer todo (?) su comportamiento. La selección natural nos induce, apoyados en lo anterior, a confiar en que el método elegido es el mejor. Y el método elegido es el matemático que se adecúa como ninguno a las leyes de la lógica interna y deductiva. Pero tiene que ser verificado por la Experiencia sensible e intelectual. Sin embargo, como hemos apuntado anteriormente, las leyes de la selección natural pueden ser discutidas, además de que hoy sabemos que las leyes evolucionan también, que algunas que fueron válidas en otro tiempo (y por lo mismo también se verificaban en la Experiencia) no lo son en la actualidad, o sólo para un campo muy restringido. A estas dificultades vienen a sumarse las modernas teorías de los sistemas que nos indican con claridad meridiana que ningún sistema, aunque su coherencia interna sea precisa, puede explicarse desde "dentro", por donde tiene que verificarse en la Experiencia sensible e intelectual. Pero si a esto añadimos la conocida frase de Einstein: "Si la matemática es verdadera entonces no coincide con lo real, y si coincide con lo real, entonces no es verdadera", lo que le sitúa en el otro extremo de Pitágoras: "La realidad es de índole matemática", además de ser una lanza contra la verificación experiencial, tendríamos que optar por un "buen" término medio que "valdría" igualmente como los dos anteriores, y que podría formularse: "Todos los sistemas están 'inventados' para equivaler y de hecho equivalen si su lógica está tan bien trabada que puedan ser aceptados por una comunidad de pensamiento, que en ese momento evolutivo coincida con la evolución de los sistemas equivalentes, no siendo necesaria por tanto la coincidencia con lo real». Este sofisma «tautológico» podría salvar la tautología de las leyes y de los sistemas. 
Pero viniendo a nuestro caso: ¿Es la perspectiva más equivalente con las leyes que rigen la disposición de los cuerpos en el espacio, con las leyes visuales, etc., o menos que otros sistemas de representación? Según Gombrich la perspectiva es más equivalente si se toma el punto de vista del "testigo ocular", esto es, si se elimina de la representación lo que no se puede ver desde un punto de vista determinado (contando con las condiciones de inmovilidad, unicidad, etc). En este sentido la perspectiva acota un campo equivalente "negativamente" con lo real, y por ende es «más equivalente" que cualquier otro sistema. Pero sólo en este sentido. Por eso habrá que racionalizar al máximo, incluso cuando observamos una obra pictórica resuelta con este sistema, ya que al ponernos en presencia de tal cuadro nuestra visión no adopta el punto de vista único, sino que recorremos la obra con otras experiencias visuales y ópticas, y acotamos en un momento más de lo que la obra acota, o nos detenemos en partes que en el propio cuadro no corresponden o no equivalen a su representación, pues llevados al extremo de inmovilidad y punto único exigido por la perspectiva solo nos fijaríamos en un punto: el punto de fuga (el blanco en el tiro al blanco). Pero al ponernos en presencia de un cuadro no "perspectiveamos" sino que vemos o percibimos, es decir, volvemos al problema de la experiencia visual, no al de la representación. Pero aquí tratamos sólo de representación. Por eso, el hecho de que nuestra experiencia visual, nuestra forma de ver, nuestra percepción sea mucho más compleja no invalida la "equivalencia» de las leyes de la perpectiva. De facto la cámara fotográfica se adecúa a estas leyes y todos interpretamos perfectamente la información que recibimos a traves de la fotografía, aunque también es evidente que esta interpretación no es natural y se necesita un aprendizaje como han demostrado los antropólogos y los pedagogos.

Aunque parezca paradójico la búsqueda de esta equivalencia se debe al progreso del naturalismo en la Edad Media, ya que conduce a interrogarse sobre la convicción de la imágenes. El ascenso del naturalismo que hemos visto en la evolución de la representación de María, no era de recibo al principio, de ahí la Theótocos o el Pantocrator. El arte sacro, cuanto más sacro, menos se interroga sobre las imágenes verosímiles o convincentes, ya que existen "nichos" o convenciones simbólicas, ideológicas, religiosas que explican perfectamente la realidad o el acontecimiento, pues la verificación se compadece con la aceptación por una comunidad. Pero la naturaleza, observada minuciosamente desde el «franciscanismo" (entendiendo por tal toda una posición del hombre medieval) anticipa imágenes convincentes, convicción que el hombre del Renacimiento comienza a echar en falta mas analíticamente en las representaciones plásticas, máxime cuando en el teatro, a pesar de muchos con- 
vencionalismos y simbolismos se ponen de manifiesto. Por ejemplo: si se representa el Nacimiento de Jesús, los personajes reales proyectan sombras, según estén iluminados los actores, algo que no ocurre en la plástica. El Niño es real y de tamaño real, o las ovejas o los pastores, etc., muy distinto de las obras pictóricas, por lo que ya avisó Leonardo de la necesidad de hacer tanteos que se acomoden ora a lo real ora a las apariencias. Los personajes del teatro ocupan un espacio real, locativo, y cuando se quedan quietos formando un "cuadro" se notan claramente las diferencias con un "cuadro pintado". Así la imagen vista en la representación teatral, aunque sea fija, "como desde una ventana", acota un espacio reconocible y medible, y enmarca unos personajes también reconocibles y cuantos. El deseo de llevar a la plástica este ureconocimiento" a la vez que limitar las incongruencias (la ausencia de sombras, p.e.) es el motor que induce a buscar un sistema igualmente convencional pero fijo e inmutable, o mejor, mensurable, que simplifique el reconocimiento de la imagen. Lo mismo que ocurría en la Astronomía, ya que de otra manera, las interpretaciones varían demasiado para fundar una ciencia, ya que los errores o desviaciones en astronomía se pagan en miles de $\mathrm{km}$. Es este sentido la ciencia aventaja al arte, como se puede comprender por la "cartografía" o la "fotografía" mas fáciles de interpretar, aunque tengan que utilizar unas convenciones fijas. Esto es, que comunican mas noticias "claras" y objetivas, aunque menos complejas. A veces muy pocas noticias, pero más simples y por lo mismo más fáciles de comprobación. Estas convenciones comportan ademas una serie de ventajas que podríamos resumir en: Constancia (la convención es constante), Consistencia (la convención se basta a sí misma), Coherencia (la convención es lógica internamente) y Verificación, ya que todo sistema coherente, constante y consistente verifica "algo", pues es «inventado" para acertar. Así sabemos que los griegos predecian eclipses aun partiendo de sistemas cósmicos erróneos. La condición es sin embargo indispensable para la convención. El acierto consiste, bien en formular exactamente las condiciones bajo las que puede aplicarse (en la perspectiva son evidentes: espacio infinito, leyes ópticas, exclusión de paralajes, exclusión de la bifocalidad...), bien en ser aceptado por una comunidad humana, que es en lo que realmente consiste la verificación. La experiencia sensible se adapta a lo que llamamos "reconocimiento", esto es, a un cúmulo de «rasgos", que, en la vida real, nos permiten descubrir el significado. Estos rasgos vienen a ser interdependientes de las sensaciones, percepciones, tanto visuales o táctiles, tanteos, fracasos, éxitos... Así, p.e., un hierro «rojo» significa calor por esa interdependencia. Al tocarlo quema, y la memoria propia o colectiva lo clasifica unido al calor y la consecuencia. A la ciencia le competirá explicar la causa tanio del color como del calor. 
Las reglas de verificabilidad tienen dos vertientes: una, su propia lógica interna, convencional, sistemática, que hemos referido más arriba y que se constituye en conocimiento (y experiencia) intelectual. Otra, que también hemos apuntado y es por lo demás tan importante como la anterior: la aceptación por una comunidad. En todo descubrimiento científico existe primero una "hipótesis", basada en las experiencias sensible e intelectual, a partir de las cuales "busca" un sistema de coherencia interna y posteriormente se verifica. Lo más llamativo es que esta verificación consiste en la aceptación, y que como dice Hawking y otros muchos autores existen teorías matemáticamente absurdas (esto es, sin coherencia interna y exageradamente convencionales) que son válidas en la práctica, y al contrario. Con la perspectiva ocurre que no existió ninguna hipótesis. $Y$ en el campo del arte ni siquiera un sistema coherente científico, ya que las leyes de la perspectiva no se codificaron científicamente sino mucho despues (finales del XVII), y los artistas las aplicaron según su "entender", con la diferencia de que unos, que las siguieron mas estríctamente resultan estéticamente los peores (p.e., Ucello en la Batalla de San Romano) mientras que otros, p.e. Masaccio en su famosa "Trinidad» de Santa María Novella de Florencia, las sigue en parte y en parte prescinde, consiguiendo una obra mucho más interesante que ninguna de Ucello, al menos en nuestra opinión y que podríamos razonar, lo que Leonardo previó con claridad y por eso lo deja bien avisado en su tratado de la pintura. Así pues, nos parece que Ucello retrocede (su obra citada es de 1456 y la citada de Masaccio es de 1427) impulsado estéticamente por el aspecto codificador de lo científico, cuando ya no hacia falta, pues el arte de representar en perspectiva estaba en el ánimo de todos y era dominada su técnica, por lo que comenzaba a decaer su lógica interna, una vez aceptada su convención fundamental. La perspectiva rigurosamente aplicada se quedaría para la geometría, la proyección, el dibujo técnico o lineal, los planos arquitectónicos... pero no para las artes plásticas que sólo aceptarían, como hemos dicho, la visión convencional, pero no hasta los extremos rigurosos de lo científico. "La caída de los ángulos" como significativamente diría Cocteau, comenzó enseguida.

Por todas estas razones es por lo que pensamos que la perspectiva en el Renacimiento no es un "descubrimiento" en el sentido científico del término, sino como mucho un "desvelamiento", una "epifanía" para la que el hombre estaba dispuesto por una evolución del naturalismo, del sistema de representación teatral, de la creación del espacio como sistema cartográfico de "colocación" de los cuerpos, del punto de vista único astronómico... Añadido todo esto y sin restar ningún mérito, a un conocimiento de la geometría y de la óptica, de la mecánica y de la física de la luz, nuevo. Pero sobre todo a una concepción laica del puesto del hombre 
en el cosmos, que tiene ahora que recurrir a leyes que le garanticen la seguridad perdida al abandonar el "teocentrismo". Por estas razón "quiere» ver el mundo como Dios lo ha visto (aún es religioso) y busca la adecuación de las leyes naturales con las del conocimiento humano, venidas ambas paralelamente de la divinidad.

Así pues, el hombre del Renacimiento tuvo la audacia de asimilar (reducir) el espacio psicofísico (natural) al matemático (lógico) en la confianza de que ambos procedían de la misma fuente. La variación de acento es fundamental. Aun aceptando que todo viene de Dios, el espacio matemático es creado-pensado por el hombre directamente, quien «mete» en el mismo todo lo creado por Dios, esto es, el espacio natural y los cuerpos extensos. De aquí la pervivencia del sistema perspectivo. Mientras el hombre occidental ha sido religioso no podía ser de otro modo. También el hombre actual sigue siendo religioso más de lo que parece y por eso la perspectiva continúa asomando también más de lo que parece en la plástica. Esta simbiosis religiosidad-laicidad resulta imprescindible para el sistema perspectivesco.

Por otra parte en el mundo real percibimos tres dimensiones lo que coincide con el hecho de que el hombre no podría vivir en una, dos o más de tres dimensiones sino exactamente en tres, pues la gravedad en esas otras dimensiones resulta inestable para el hombre. Esta ley física que parece actualmente demostrada (?) ha condicionado enormemente la persistencia de la representación según el modelo de la perspectiva geométrica, ya que coincide mejor que otras formas de representación con las leyes ópticas elementales (que no complejas), como se pone de manifiesto en la cámara oscura o fotográfica. Por eso el Renacimiento no intenta una ley de representación ni una ilusión óptica, sino sólo una concordancia con las leyes ópticas y naturales mediante una convención matemática que "reproduzca» la apariencia de las tres dimensiones. Conseguida y aceptada tal convención, no la exagera científicamente hablando (al menos los mejores artistas), pero perdura con fuerza tal tipo de reproducción que "equivale" a la realidad, aunque no se ajuste totalmente, por su sencillez de codificación y de coherencia interna. Los artistas geniales se dieron cuenta enseguida de la importancia, pero también de la limitación de esta equivalencia. $Y$ el mundo occidental aceptó y continúa aceptando esta equivalencia, aun sabiendo que equivalencia no es igualdad y que por lo mismo existen otras equivalencias. Del mismo modo que aun conociendo las geometrías no euclideas seguimos prácticamente utilizando casi exclusivamente la geometría de Euclides, salvo para casos muy específicos y sólo por expertos. $Y$ esto demuestra aún m-ás nuestro criterio de que la perspectiva no fue un descubrimiento sino la aceptación, y por lo mismo la verificación, por parte del hombre occidental de su 
nuevo papel en el cosmos, que no ha abandonado todavía a pesar de los esfuerzos del arte (cubismo, p.e.) y de la ciencia (la relatividad, la indeterminación, p.e.) por cambiar esta posición.

\section{CONCLUSIONES}

La evolución empírica por sí sola no hubiera llegado al desvelamiento de la perspectiva. Por la línea empírica es posible que se hubiera caminado hacia otras soluciones, incluso mas reales, pero menos uniformes, universales y codificadas.

La perspectiva no es descubrimiento en el sentido riguroso, ya que no parte de hipótesis alguna, no es un sistema completo ya que, al menos en la representación artística, debe ser corregido para no deformar lo real y sólo es equivalente a la realidad en unas condiciones muy concretas y precisamente negativas. Es lo que los escolásticos llamarían de utertio excluso».

Tanto la línea empírica como la abstracción perspectivesca avanzaron paralelamente, por eso no son continuas, ya que dependen de un cambio de mentalidad en el concepto de espacio y su representación. Este cambio se va produciendo lentamente a lo largo de la Edad Media por los descubrimientos empíricos y los conocimientos científicos. Pero especialmente por la situación del hombre en el cosmos y su relación con el mismo, ahora muy analizada a partir de la Astronomía que adopta el modelo cuántico, matemático.

La perspectiva eclosiona gracias a este cambio de mentalidad que busca denodadamente una objetivación, una ley, una regla que pueda convertirse en universal, aunque sea convencional.

El hombre renacentista indaga en el método matemático (construcción humana) y su equivalencia, que no igualdad, con lo real (construcción divina o natural) aunque el renacentista cree en la igualdad entusiasmado por su hallazgo.

Descubre la validez de tal metodo o mejor "verifica" su validez, ya que está deseando "acertar" y está preparado mentalmente para aceptar un sistema que "acote" una parcela de lo real.

Dado que toda "acotación" (ejemplo de la astronomía) es objetivable, medible, y cuantificable resulta una referencia precisa y universal, y respetadas las condiciones metodológicas no es errónea, esto es, predice y acierta. 
La perspectiva, respetadas las drásticas condiciones en que se mueve, equivale a una parcela de lo real, bien que pequeña y negativa, pero suficiente para informar de una manera "neutra», dejando las complejidades infinitas de lo real, imposibles de codificar.

Aceptada esta codificación, aunque deformante e irreal como vieron Leonardo y Einstein por citar algunos, el entramado lógico y coherente del sistema es férreo, lo que induce al hombre renacentista a una exultante aceptación pues su mentalidad está deseosa de esta demostración humanista: ver el mundo como Dios, aunque sea como Dios con un solo ojo.

Mientras la física y la ideología religiosa se han combinado el triunfo de la perspectiva está asegurado, aunque con correcciones desde el principio. Los embates, desde el impresionismo tímidamente, pero más fuertes desde las vanguardias del siglo xx por parte del arte, de la física moderna, de la teoría de la percepción y de las ideologías han contribuido a situar la perspectiva en su sitio, esto es, en un "modo" ni el único ni el mejor, de representar el mundo tridimensional en que vivimos.

Pero otros descubrimientos, la fotografía, el cine, la televisión, especial y espectacularmente, han argumentado en favor de la perspectiva como medio «engañoso" (MANKIEWICZ en 1973: "Trabajamos para crear una irrealidad que parecerá real a millones de espectadores") aprovechando la mentalidad del hombre moderno muy anclada en al pasado, muy cómoda con los criterios de percepción y muy poco abierta, a pesar de la apariencias, a las demás leyes que exigen un esfuerzo por encontrar un puesto nuevo en el cosmos. Leyes de la relatividad, del azar... que no han entrado a formar parte de los modos de vida y percepción del universo con estar seriamente demostradas, y teniendo en su favor la sencillez y claridad de no presentarse como absolutas, ya que admiten la propia evolución de las leyes.

La perspectiva es únicamente una codificación sencilla y de fácil manejo, exacta en su aplicación limitada. Algo así, como una receta de cocina, que no es la comida, pero que gracias a una codificación de pesos y medidas - cuantificable y verificable - nos ilustra de la cantidad exacta de p.e. sal para tal guiso. Antes empíricamente se introducía un huevo en el líquido a salar y se añadía sal hasta que el huevo flotaba. La correspondencia de la flotación con el gusto era "apreciada" como la más equivalente. Cuando se codifican las medidas no se necesita el huevo, ya que se pueden calcular el peso específico del líquido, la sal, la saturación... y esto es lo que codifica una receta de cocina que, seguida exactamente, "funciona". En cualquier caso valga para la perspectiva la 
anécdota de Kepler, quien preguntó en una ocasión a su mujer si lanzando al cosmos lechuga, sal, vinagre y aceite se formaría una ensalada. A lo que la mujer contestó: "Es posible, pero nunca tan sabrosa como la que yo te preparo". Entre el azar y la necesidad, el arte, el gran arte, también el gran arte del Renacimiento, elige siempre otros caminos. 